\title{
Research Paper: The Effects of Mindfulness-based Stress Reduction Group Therapy on Anxiety, Depression, Stress, and the Intolerance of Uncertainty in Infertile Women
}

Elnaz Mousavi ${ }^{1}$ (D), Sedighe Hosseini ${ }^{2}$ (D), Maryam Bakhtiyari ${ }^{3}$ (D), Imaneh Abasi ${ }^{3}$ (D), Abolfazl Mohammadi , Abbas Masjedi Arani $^{* *}$ (i)

1. Department of Clinical Psychology, Faculty of Medicine, Zanjan University of Medical Sciences, Zanjan, Iran

2. In Vitro Fertilization (IVF Center), Taleghani Hospital, Shahid Beheshti University of Medical Sciences, Tehran, Iran.

3. Depatment of Clinical Psychology, School of Medicine, Shahid Beheshti University of Medical Sciences, Tehran, Iran.

4. Department of Psychiatry, School of Medicine, Tehran University of Medical Sciences, Tehran, Iran.

5. Department of Community Medicine, Quran and Hadith Reasearch Center, Faculty of Medicine, Baqiyatallah University of Medical Sciences, Tehran, Iran.

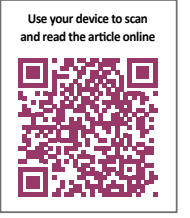

Cltation: Mousavi E, Hosseini S, Bakhtiyari M, Abasi I, Mohammadi A, Masjedi Arani A. The Effects of Mindfulness-based Stress Reduction Group Therapy on Anxiety, Depression, Stress, and the Intolerance of Uncertainty in Infertile Women. Iranian Rehabilitation Journal. 2020; 18(2):137-144. http://dx.doi.org/10.32598/irj.18.2.862.1

\section{(c) (1) (8)}

Article info:

Received: 11 Jan 2019

Accepted: 03 Jul 2019

Available Online: 01 Jun 2020

Keywords:

Mindfulness-based

stress reduction, Anxiety,

Depression, Stress, Intolerance

of uncertainty, In vitro

Fertilization (IVF)

\section{ABSTRACT}

Objectives: The present study aimed to examine the effects of Mindfulness-Based Stress Reduction (MBSR) group therapy on anxiety, depression, stress, and the Intolerance of Uncertainty (IU) in infertile women receiving In Vitro Fertilization (IVF).

Methods: This was a randomized clinical trial with a pre-test/post-test and 3-month followup design. The study sample included 30 women with infertility who referred to Taleghani Hospital in Tehran City, Iran in 2018. We enrolled 30 individuals in the present study. The study samples were randomly divided into two groups of experimental and control ( $n=15 /$ group). All study participants completed the Depression Anxiety Stress Scale (DASS), and the Intolerance of Uncertainty Scale (IUS) before and after providing the intervention. Data analysis was conducted using SPSS.

Results: The current research results revealed a significant difference between the MBSR and control groups in IU, stress, depression, and anxiety. Furthermore, there were significant differences in all dependent variables between pre-test and post-test scores except for IU in the experimental group.

Discussion: The provided MBSR group therapy could reduce the rate of depression, anxiety, and stress in infertile women receiving IVF; however, it presented no significant effect on IU. In other words, IU may be a complex phenomenon, i.e. amenable to treatment and further studies are required to examine its reasons.

\section{* Corresponding Author: \\ Abbas Masjedi Arani, PhD.}

Address: Department of Community Medicine, Quran and Hadith Reasearch Center, Faculty of Medicine, Baqiyatallah University of Medical Sciences,

Tehran, Iran.

Tel: +98 (21) 23031548

E-mail: doctormasjedi@yahoo.com 


\section{Highlights}

- Stress, depression, anxiety, and IU levels were high in infertile women receiving IVF.

- MBSR group therapy could decrease anxiety, stress, and depression in the studied sample. However, it had no significant effect on IU in this group.

\section{Plain Language Summary}

All of the studies revealed that factors, such as depression or anxiety could threaten infertility treatment outcomes. Besides, by improving mental health, psychological interventions together with infertility treatment, could enhance the effectiveness of infertility treatments. Therefore, researchers suggested that an infertility treatment program must be accompanied by psychological treatment. MBSR group therapy is a third-generation of cognitive-behavioral therapies. This intervention could decrease anxiety, stress, and depression in infertile women receiving IVF after finishing the treatment sessions.

\section{Introduction}

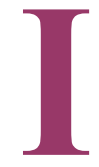

nfertility is a complex problem that affects the life of approximately 80 million individuals in the world. Furthermore, it is estimated that mental problems in infertile people range from $60 \%-25 \%$, and in particular, anxiety and depression in infertile groups [1]. Stress, depression, anger, and anxiety are associated with infertility in women [2]. Numerous studies demonstrated that mental health factors, e.g. depression or anxiety could threaten infertility treatment outcomes [3]. In addition to anxiety and depression, many psychological variables affect the treatment outcomes in infertile individuals [4]. For example, the Intolerance of Uncertainty (IU) affects the rate of depression, anxiety, and stress in this population. The IU could be defined as a cognitive bias on how individuals perceive, interpret, and respond to uncertain situations, which affects their cognitive, emotional, and behavioral aspects [5].

Some early psychological theories have suggested that the tendency to avoid uncertainties significantly impact the severity and continuation of depression and anxiety [6]. The initiation of infertility interventions is regularly a difficult decision for the couples. This is because it is connected with the stress associated with the inability to naturally become pregnant and losing control over their bodies. There are some approaches for fertility that intrauterine insemination; In Vitro Fertilization (IVF) is one of these methods [7]. Many of the infertile couples end up using IVF as a procedure of fertility. A consequence of such interventions is the increased stress level and the outcome of the IVF process [8]. Therefore, researchers suggested that an infertility treatment program must be accompanied by psychological treatment [9].
The Mindfulness-based Stress Reduction (MBSR) program is a third-generation of cognitive-behavioral therapies. MBSR includes education about stress as well as training in coping strategies. MBSR involves the development of some attitudes, including becoming an unbiased witness to one's own experience; the acceptance of matters as they are in the present moment; and not censoring thoughts and allowing them to come and go [10]. Li et al [4] argued that mindfulness helped infertile women to cope with IVF in adaptive manners. Additionally, Aslzaker [11] suggested that MBSR is effective in the success of IVF and psychological symptoms in women receiving IVF.

Infertility may not be regarded as a medical problem; however, because each couple suffering from this issue spends a lot of time and money to solve this matter. They also have many relatives might pressurize them; thus, studying infertility is necessary [12]. Investigating the most effective psychological interventions to reduce anxiety, depression, stress, and IU in infertile women could be sensitive and constructive in improving the effects of moderen infertility treatments and reduce the failure of IVF therapy in this group. Exploring IU has been neglected in previous studies. Therefore, this study aimed to investigate the effects of MBSR group therapy on anxiety, depression, stress, and IU in infertile women receiving IVF

\section{Methods}

This was a clinical trial with a pre-test/post-test and a control group design. The statistical population of this study was infertile women aged 20-45 years presenting the symptoms of anxiety and depression in Tehran 


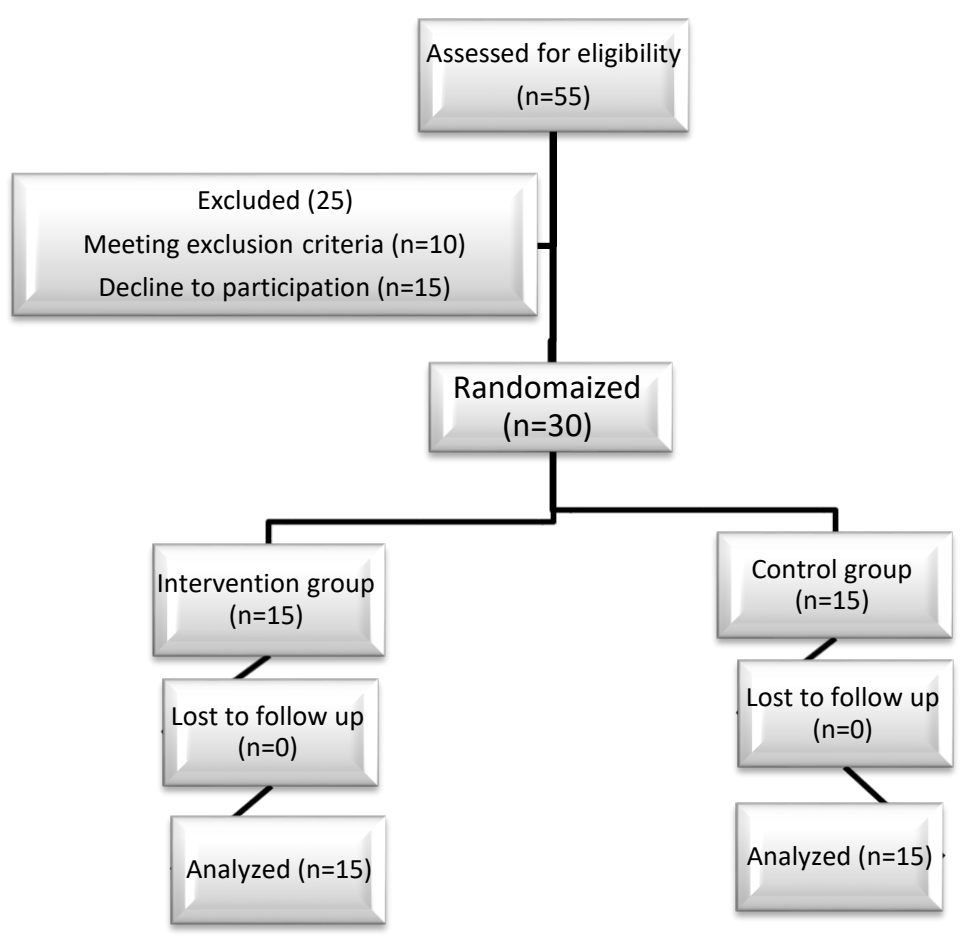

Figure 1. The study participants' flow chart

Iranian Rehabilitation Journa

Province, Iran, in 2017-2018. The study participants consisted of 30 infertile women with their age ranging from 26 to 43 years (Mean \pm SD: $35.23 \pm 4.95$ ) referring to Taleghani Hospital in Tehran City, Iran in 2017-2018. The required sample size was calculated based on $G^{*}$ Power software with an alpha error of 0.05 and a beta error of 0.2 . Besides, the effect size equaled 0.25 , and the number of repetitions was equal to 3 . The study participants were randomly assigned to the study groups. In terms of educational level, 3.3\%, 43.3\%, 36.7\%, and $16.7 \%$ were identified as under diploma, diploma, bachelor's degree, and master's degree, respectively.

After referral by infertility specialist, the study subjects were selected using The Structured Clinical Interview for DSM-IV Axis I Disorders (SCID-I) and The Structured Clinical Interview for DSM-IV Axis II Disorders (SCID-II). We employed a purposive sampling method for selecting the study samples. The study inclusion criteria were as follows: at least one year past marriage, receiving a definite diagnosis of infertility, having elementary education and higher, women aged $20-45$ years, the lack of receiving prior IVF/ICSI treatment, agreeing to participate in the treatment, the lack of hormonal and genital diseases, no history of separation and remarriage, not having a child, no history of acute psychiatric disorders, and not consuming psychiatric medications. Additionally, the study exclusion criteria were as follows: absence from more than two sessions of MBSR treatment, ant no willingness to continue the treatment. The flowchart of study participants is listed in Figure 1.

The Depression Anxiety Stress Scale (DASS), and the Intolerance of Uncertainty Scale (IUS) were administered for data collection. The research participants in the MBSR group $(n=15)$ received therapy for 8 weekly sessions ( 2 hours); however, the control group $(n=15)$ received no treatment. The diagnostic evaluation tools were administered at pre-test, post-test, and the 3-month follow-up stages. A summary of functional instruction sessions of MBSR is illustrated in Table 1. The therapist of the present study was a $\mathrm{PhD}$. student of Clinical Psychology and had already received the training and courses for MBSR. Moreover, the evaluator of this study held a master's degree in Clinical Psychology to avoid bias concerning the study findings. The obtained data were analyzed using SPSS.

The below instruments were used in the present research.

\section{Structured Clinical Interview (SCID-I/SCID-II)}

This tool was developed by Frist et al. in 1997. It is used for diagnosis based on 4 criteria of the Diagnostic and Statistical Manual of Mental Disorders- Fourth Edi- 
Table 1. A summary of functional instruction sessions of MBSR

\begin{tabular}{|c|c|}
\hline Sessions & Contents \\
\hline First & $\begin{array}{l}\text { The introduction of automatic guidance system/knowing how to use present moment awareness of bodily sensations, } \\
\text { thoughts, and emotions in reducing stress/practicing in eating raisins practice, and 1-, 3-minute breathing practice }\end{array}$ \\
\hline Second & $\begin{array}{l}\text { Re-examining body training/giving feedback and discussion in examining body training/ breathing-based mindfulness } \\
\text { meditation }\end{array}$ \\
\hline Third & Practicing mindfulness-based sitting with the awareness of breathing/practicing yoga exercise/three-minute breathing \\
\hline Fourth & $\begin{array}{l}\text { Re-examining body training/practicing exercises concerning conscious yoga/5-minute practicing of "seeing or hearing"/ } \\
\text { re-practicing consciousness session with awareness about breathing and body }\end{array}$ \\
\hline Fifth & $\begin{array}{l}\text { Practicing breathing/re-practicing consciousness session/explaining stress and recognizing the research participants' } \\
\text { reactions to stress/examining awareness about pleasant and unpleasant situations concerning feelings, thoughts, and } \\
\text { bodily sensations/practicing conscious yoga exercises/practicing 3-minute breathing /distributing leaflets }\end{array}$ \\
\hline Sixth & Practicing conscious yoga/practicing sitting meditation/distributing leaflets \\
\hline Seventh & $\begin{array}{l}\text { Practicing mountain meditation/discussing sleep hygiene/repeating the exercises of the prior session/practicing several } \\
\text { enjoyable activities/distributing the leaflets of the seventh session }\end{array}$ \\
\hline Eighth & Examining body training/providing a summary of the program/examining and conversing programs \\
\hline
\end{tabular}

* Retrieved from the program of Kabat-Zinn

Iranian Rehabilitation \ournal

tion (DSM-IV). SCID has two versions; 1- SCID-I for assessing axis I. This tool has excellent validity and reliability. For instance, Bakhtiari's study (2000) has supported the validity of this tool. 2- SCID-II is employed for assessing axis II. It measures 10 personality disorders, based on DSM-IV criteria, as well as a passive personality disorder. In Bakhtiari's study, the content validity of the translated version of the tool was established by three professors of Psychology. Additionally, the testretest reliability coefficient of this tool with an interval of one week was calculated as $87 \%$ [13].

\section{The 21-item Anxiety, Depression, and Stress Scale (DASS-21)}

The short form of this scale with 42 questions has been generated by Leviband in 1995. Its test-retest reliability for depression, anxiety, and stress is reported to be $80 \%, 76 \%$, and $77 \%$. Moreover, these aspects' Chronbach's alpha coefficient was measured as $81 \%, 79 \%$, and $78 \%$, respectively. The validity of this tool was examined by confirmatory factor analysis and components method. The cut-off points of anxiety, depression, and stress were reported as 7, 9, and 14, respectively [14]. In Sahebi's study, the reliability of this tool for depression, anxiety, and stress were reported $0.77,0.79$, and 0.78 , respectively [13].

\section{The Intolerance of Uncertainty Scale (IUS)}

This scale was designed by Freestone. The test has 27 questions, i.e. related to unacceptability and ambiguity. This test is answered on a five-point Likert-type scale (never, rarely, sometimes, often, \& always). Besides, each option is scored with $1,2,3,4$, and 5 , respectively. The cut-off point of the questionnaire was measured as 54 [15]. In the French version, the internal consistency (0.91) and a relatively good retest reliability coefficient were obtained with a 4-week interval (0.78). The coefficient of the validity of this test was reported to be significant and satisfactory [16]. In the research of Alizadeh, Hasanzadeh, Aliloo, and Poursharifi, the Cronbach's alpha coefficient of the total uncertainty imbalance was computed as 0.69 [17].

\section{Results}

Adherence was measured by the percentage of completed prescribed homework. About $90 \%$ of homework was completed by the study participants. There was no drop out in the treatment group during the intervention and at the follow-up stage. Before analyzing the differences between MBSR and control groups in study variables, the differences in demographic variables were examined. The results of the Independent Samples t-test and Chisquared test demonstrated no significant differences in 
Table 2. The mean and standard deviation scores of the studied dependent variables in the MBSR and control groups

\begin{tabular}{ccccccc}
\hline & \multicolumn{5}{c}{ Mean \pm SD } \\
\cline { 2 - 7 } Variables & \multicolumn{3}{c}{ Control } & \multicolumn{3}{c}{ MBSR } \\
\cline { 2 - 7 } & Pre-test & Post-test & Follow-up & Pre-test & Post-test & Follow-up \\
\cline { 2 - 7 } & $7.06 \pm 2.01$ & $7.46 \pm 1.59$ & $8.00 \pm 1.60$ & $7.26 \pm 1.66$ & $5.00 \pm 1.51$ & $4.86 \pm 1.45$ \\
\hline Stress & $68.33 \pm 14.85$ & $71.66 \pm 17.34$ & $74.20 \pm 15.17$ & $61.80 \pm 13.03$ & $57.26 \pm 13.12$ & $56.46 \pm 13.88$ \\
IU & $13.40 \pm 1.50$ & $14.20 \pm 1.93$ & $14.40 \pm 1.76$ & $15.00 \pm 1.69$ & $10.40 \pm 1.54$ & $9.40 \pm 11.40$ \\
\hline Depression & $12.33 \pm 1.54$ & $13.53 \pm 1.40$ & $14.26 \pm 1.75$ & $13.46 \pm 1.45$ & $10.00 \pm 1.51$ & $9.13 \pm 1.50$ \\
\hline
\end{tabular}

Iranian Rehabilitation Journa

Table 3. Paired Samples t-test data and the effect size of the explored dependent variables

\begin{tabular}{ccccccccccc}
\hline \multirow{2}{*}{ Variables } & \multicolumn{3}{c}{ Baseline to Post-test } & \multicolumn{3}{c}{ Post-test to Follow-up } & \multicolumn{3}{c}{ Baseline to Follow-up } \\
\cline { 2 - 10 } & $\mathbf{t}_{14}$ & $\mathbf{P}$ & Hedges' $\mathbf{g}$ & $\mathbf{t}_{14}$ & $\mathbf{P}$ & Hedges' $\mathbf{g}$ & $\mathbf{t}_{14}$ & $\mathbf{P}$ & Hedges' $\mathbf{g}$ \\
\hline IU & 1.43 & 0.17 & 0.33 & 1.63 & 0.12 & 0.05 & 1.49 & 0.15 & 0.38 \\
Stress & 9.93 & 0.001 & 1.38 & 1.46 & 0.16 & 0.09 & 9.43 & 0.001 & 1.49 \\
Depression & 15.89 & 0.001 & 2.76 & 5.91 & 0.001 & 0.11 & 17.46 & 0.001 & 0.66 \\
Anxiety & 12.66 & 0.001 & 2.26 & 6.50 & 0.001 & 0.56 & 13.59 & 0.001 & 2.84 \\
\hline
\end{tabular}

Iranian Rehabilitation Dourna

age $\left(\mathrm{t}_{28}=-1.07, \mathrm{P}<0.29\right)$ and educational level $\left(\chi(3)^{2}=1.36\right.$, $\mathrm{P}=0.73)$ between the MBSR and control groups.

At baseline assessment, there were no significant differences between the study groups in stress $\left(\mathrm{t}_{28}=-1.28\right.$, $\mathrm{P}=0.21)$ and $\mathrm{IU}\left(\mathrm{t}_{28}=0.29, \mathrm{P}=0.76\right)$; however, there were significant differences between the research groups in depression $\left(\mathrm{t}_{28}=2.74, \mathrm{P}=0.01\right)$ and anxiety $\left(\mathrm{t}_{28}=2.06\right.$, $\mathrm{P}=0.04$ ) symptoms.

The Mean \pm SD age of the control and MBSR groups was $36.20 \pm 5.11$ and $34.27 \pm 4.75$ years, respectively. The Mean \pm SD scores of the explored dependent variables are presented in Table 2. The Independent Samples t-test and Analysis of Covariance (ANCOVA) (after assessing the homogeneity of variances, i.e. not significant) were implemented to examine the differences between groups in terms of the dependent variables. The relevant results indicated a significant difference between the MBSR and control groups in $\mathrm{IU}\left(\mathrm{t}_{28}=-2.56, \mathrm{P}<0.01\right)$, stress $\left(\mathrm{t}_{28}=-4.34, \mathrm{P}<0.001\right)$, depression $\left(\mathrm{F}_{1,28}=122.33, \mathrm{P}<0.001\right.$, $\left.\eta^{2}=0.81\right)$, and anxiety $\left(\mathrm{F}_{1,28}=105.22, \mathrm{P}<0.001, \eta^{2}=0.79\right)$. Furthermore, to examine the effects of MBSR on the dependent variables and whether treatment efficacy was maintained at the 3-months follow-up, a Paired Samples t-test was conducted (Table 3). The obtained data suggested significant differences in all explored dependent variables between pre-test and post-test phases scores, except for IU.
To assess clinical significance, the total mean value of the experimental group concerning stress, depression, anxiety, and IU was assessed after conducting the intervention. All mean scores were below the mentioned cutoff point (stress: 5, depression: 10.40, \& anxiety: 10), except for IU (57.26).

\section{Discussion}

The current study examined the effectiveness of MBSR group therapy on anxiety, depression, stress, and IU in infertile women receiving IVF. The collected results suggested that MBSR is effective on anxiety, depression, the stress in infertile women receiving IVF; however, it had no significant effect on IU in the studied females. The obtained data concerning the effectiveness of this treatment on anxiety, depression, and stress were consistent with the study of Li [4], Baer [18], Dembinska [19], Aslzaker [11], and Nery [13]. Theorists have suggested that MBSR may decrease the symptoms of stress, anxiety, and depression by adjusting emotion regulation skills [20].

Furthermore, clinical observations highlighted that IU plays an essential role in increasing worry and rumination [21]. Concerning the effectiveness of MBSR on IU in this group, the current research results suggested no effects of the provided treatment on IU in the investigated participants. This finding was consistent with those of previous research [22]. However, they were inconsistent 
with the results of Vered Miriam [23] and Lee [24]. In explaining our results, research reflects a correlation between IU and metacognition, i.e. anticipated that both factors play critical roles in maintaining worry. It could be hypothesized that having certain thoughts about cognitions could affect how one processes the content of thoughts, especially those about uncertainty [25]. Thus, IU is a potential characteristic in infertile women receiving IVF and psychopathology at the "macro" cognitive level; that is why MBSR was ineffective on it.

MBSR techniques are more effective in changing emotions [20]. Furthermore, IU is more of a cognitive component rather than an emotional one; thus, probably because of this, the treatment failed to affect it. Another explanation is that clients with high IU experience substantial discomfort when confronting uncertainty. Such a condition causes them to be highly motivated to avoid or minimize any aspects of psychotherapy that focus on change. This may cause them to avoid confronting their problems during the action stage of therapy [26]. Moreover, another reason for gaining this result might be the applied questionnaire that fails to match our culture [15].

Limiting the study sample to Tehran restricts the generalizability of the obtained results to other regions. Another limitation of the study was the lack of involvement of men in the program, which also reduces the generalizability of the results. The lack of specific objective assessments could be considered as a factor limiting the research. Researchers suggest that the MBSR be implemented on infertile couples and to use large sample sizes. Additionally, it is recommended that further studies consider the effectiveness of other therapeutic protocols as well as the impact of IU among infertile women receiving IVF.

\section{Conclusion}

MBSR could decrease anxiety, stress, and depression in infertile women receiving IVF; these therapeutic outcomes remained at a 3-month follow-up, especially for depression, anxiety, and stress symptoms. However in terms of the IU, due to the nature of this variable, the treatment type and the impact of the questionnaire were not effective and significant.

\section{Ethical Considerations}

\section{Compliance with ethical guidelines}

The study was approved by the Ethics Committee of Shahid Behesht University of Medical Sciences (Code: IR.SBMU.MSP.REC.96233). Also all study participants were informed about the study objectives and those agreeing to participate signed the informed consent forms.

Funding

This research was financially supported by Shahid Beheshti University of Medical Sciences.

\section{Authors' contributions}

Conceptualization, supervision: Abbas Masjedi Arani; Methodology: Maryam Bakhtiyari; Investigation: Sedighe Hosseini; Writing - original draft, resources: Elnaz Mousavi; Formal analysis: Imaneh Abasi; Review \& editing: Abolfazl Mohammadi.

\section{Conflict of interest}

The authors declared no conflicts of interest

\section{References}

[1] De Berardis D, Mazza M, Marini S, Del Nibletto L, Serroni N, Pino MC, et al. Psychopathology, emotional aspects and psychological counselling in infertility: A review. La Clinica Terapeutica. 2014; 165(3):163-9. [DOI:10.7417/CT.2014.1716] [PMID]

[2] De Berardis S, Karimi S, Ahmadi V, Kokabi R, Afsordeh F. [An investigation of psychological factors related to distress feeling in the infertile women (Persian)]. Journal of Ilam University of Medical Sciences. 2014; 22(3):73-81. http://sjimu. medilam.ac.ir/article-1-1380-en.html

[3] Abedi Shargh N, Bakhshani NM, Mohebbi MD, Mahmudian Kh, Ahovan M, Mokhtari M, et al. The effectiveness of mindfulness-based cognitive group therapy on marital satisfaction and general health in woman with infertility. Global Journal of Health Science. 2016; 8(3):230-5. [DOI:10.5539/gihs. v8n3p230] [PMID] [PMCID]

[4] Li J, Long L, Liu Y, He W, Li M. Effects of a mindfulnessbased intervention on fertility quality of life and pregnancy rates among women subjected to first in vitro fertilization treatment. Behaviour Research and Therapy. 2016; 77:96-104 [DOI:10.1016/j.brat.2015.12.010] [PMID]

[5] Dugas MJ, Schwartz A, Francis K. Brief report: Intolerance of uncertainty, worry, and depression. Cognitive Therapy and Research. 2004; 28(6):835-42. [DOI:10.1007/s10608-004-0669-0]

[6] Gentes EL, Ruscio AM. A meta-analysis of the relation of intolerance of uncertainty to symptoms of generalized anxiety disorder, major depressive disorder, and obsessive-compulsive disorder. Clinical Psychology Review. 2011; 31(6):923-33. [DOI:10.1016/j.cpr.2011.05.001] [PMID]

[7] Malina A, Pooley JA. Psychological consequences of IVF fertilization - review of research. Annals of Agricultural and Environmental Medicine 2017; 24(4):554-8 [DOI:10.5604/12321966.1232085] [PMID] 
[8] Berghuis JP, Stanton AL. Adjustment to dyadic stressor: A longitudinal study of coping and depressive symptoms in infertile couples over an insemination attempt. Journal of Consulting and Clinical Psychology. 2002; 70(2):433-8. [DOI:10.1037/0022-006X.70.2.433]

[9] Boivin J. A review of psychosocial interventions in infertility. Social Science \& Medicine. 2003; 57(12):2325-41. [DOI:10.1016/ S0277-9536(03)00138-2]

[10] Marchand WR. Mindfulness-based stress reduction, mindfulness-based cognitive therapy, and Zen meditation for depression, anxiety, pain, and psychological distress. Journal of Psychiatric Practice. 2012; 18(4):233-52. [DOI:10.1097/01. pra.0000416014.53215.86] [PMID]

[11] Aslzaker M, Pourshahbaz A, Bagheri Lankarani N, Mohammadkhani P, Geranmayepour S. Effects of infertility stress, psychological symptoms, and quality of life on predicting success rate of ivf/icsi treatment in infertile women. Practice in Clinical Psychology. 2016; 4(4):275-81. http://jpcp. uswr.ac.ir/article-1-435-en.html

[12] Kormi Nouri R, Akhondi MM, Behjati Ardakani Z. [Psychosocial aspects of infertility from viewpoint of infertility treating physicians (Persian)]. Journal of Reproduction \& Infertility. 2001; 2(3):13-26. http://www.jri.ir/article/53

[13] Nery SF, Paiva SP, Vieira ÉL, Barbosa AB, Sant'Anna EM, Casalechi $\mathrm{M}$, et al. Mindfulness-based program for stress reduction in infertile women: Randomized controlled trial. Stress and Health. 2019; 35(1):49-58. https://onlinelibrary. wiley.com/doi/abs/10.1002/smi.2839

[14] Mohammadi A. [Comparison of the transdiagnostic group therapy with group cognitive therapy on indicated prevention of anxiety and depression (Persian)] [PhD. thesis]. Tehran: Tehran University of Medical Sciences; 2011. https:// fa.irct.ir/trial/4401

[15] Norton PJ. A psychometric analysis of the Intolerance of Uncertainty Scale among four racial groups. Journal of Anxiety Disorders. 2005; 19(6):699-707. [DOI:10.1016/j. janxdis.2004.08.002] [PMID]

[16] Freeston MH, Rhéaume J, Letarte H, Dugas MJ, Ladouceur R. Why do people worry? Personality and Individual Differences. 1994; 17(6):791-802. [DOI:10.1016/0191-8869(94)90048-5]

[17] Alizadeh A, Hasanzadeh L, Mahmood Aliloo M, Poursharifi $\mathrm{H}$. [Predict of worry based on behavioral activation and inhibition systems(BAS/BIS), cognitive emotion regulation and intolerance of uncertainty in students (Persian)]. Journal of Cognitive Psychology. 2014; 2(3):1-11. http:/ /jcp.khu.ac.ir/ article-1-2355-en.html

[18] Baer RA. Mindfulness training as a clinical intervention: A conceptual and empirical review. Clinical Psychology: Science and Practice. 2003; 10(2):125-43. [DOI:10.1093/clipsy.bpg015]

[19] Dembińska A. Mindfulness Based Stress Reduction in Infertility (MBSR-I)- information on the implementation of a new method. The European Health Psychologist. 2016; 18(Suppl):49-58. https://ehps.net/ehp/index.php/contents/ article/view/2249

[20] Goldin PR, Gross JJ. Effects of Mindfulness-Based Stress Reduction (MBSR) on emotion regulation in social anxiety disorder. Emotion. 2010; 10(1):83-91. [DOI:10.1037/a0018441] [PMID] [PMCID]
[21] Alimehdi M, Ehteshamzadeh P, Naderi F, Eftekhaesaadi Z, Pasha R. The effectiveness of cognitive-behavioral therapy on intolerance of uncertainty and anxiety sensitivity in patients with generalized anxiety disorder. Journal of Thought \& Behavior in Clinical Psychology. 2015; 10(38):77-86. https:// jtbcp.riau.ac.ir/article_995.html

[22] Alimehdi M, Ehteshamzadeh P, Naderi F, Eftekharsaadi $\mathrm{Z}$, Pasha R. The effectiveness of mindfulness-based stress reduction on intolerance of uncertainty and anxiety sensitivity among individuals with generalized anxiety disorder. Asian Social Science. 2016; 12(4):179-87. [DOI:10.5539/ass.v12n4p179]

[23] Vered Miriam H. Mindfulness based stress reduction in couples facing Multiple Sclerosis: Impact on self reported anxiety and uncertainty [PhD. thesis]. New York: The City University of New York; 2009. https://search.proquest.com/ openview/fd48d29f8ee832b92bd1b337e25f838d

[24] Lee SH. [Effects of mindfulness-based therapy on depressive disorder (Korean)]. Journal of Korean Neuropsychiatric Association. 2018; 57(2):133-8. [DOI:10.4306/jknpa.2018.57.2.133]

[25] Konstantellou A, Reynolds M. Intolerance of uncertainty and metacognitions in a non-clinical sample with problematic and normal eating attitudes. Eating Behaviors. 2010; 11(3):193-6. [DOI:10.1016/j.eatbeh.2010.01.003] [PMID]

[26] Leite C, Kuiper NA. Client uncertainty and the process of change in psychotherapy: The impact of individual differences in self-concept clarity and intolerance of uncertainty. Journal of Contemporary Psychotherapy. 2008; 38(2):55-64. [DOI:10.1007/s10879-007-9068-7] 
This Page Intentionally Left Blank 